\title{
Assessing the Future of Renewable Energy Consumption for United Kingdom, Turkey and Nigeria
}

\author{
Nurcan Kilinc Ata \\ Postdoctoral Researcher and Project Analyst, nurcankilinc@yahoo.com \\ University of Stirling, Stirling FK9 4LA, UK
}

\begin{abstract}
$\mathrm{T}$ he relationship between economic growth and renewable energy (RE) consumption has received enormous attention in the literature. However, there are diverse views about the causality and nature of this relationship. The paper investigates how RE consumption during power generation is affected by economic growth and electricity prices using data from 1990 to 2012. This is conducted by using three case study countries (United Kingdom, Turkey, and Nigeria). Then, a prediction

model is developed for the year 2030. The findings in this paper show that RE consumption, for the period under consideration, is significantly determined by income and electricity prices in the long run. These findings support the advantages of government policies encouraging the use of RE by implementing RE markets and $\mathrm{RE}$ portfolio standards to not only enhance the security and environmental concerns, but also from a macroeconomic point of view (stable economic growth).
\end{abstract}

Keywords: renewable energy; energy consumption; economic growth; forecasting; vector auto-regression; international comparisons; United Kingdom; Turkey; Nigeria
Citation: Kilinc-Ata N. (2018) Assessing the Future of Renewable Energy Consumption for United Kingdom, Turkey and Nigeria. Foresight and STI Governance, vol. 12, no 4, pp. 62-77. DOI: 10.17323/2500-2597.2018.4.62.77 
$\mathrm{T}$ he relationship between energy consumption and economic growth is well established. Securing abundant, affordable energy is critical to manufacturing, infrastructure expansion, transportation, and increasing standards of living. However, less is known about the relationship between renewable energy (RE) consumption and economic growth. Countries of varying economic positions encourage interest in RE for a variety of reasons related to improving the standard of living for their citizens. Developed countries want to encourage the expansion of RE sources to strengthen the energy security of supply and address climate change [Edenhofer et al., 2013; Hocaoglu, Karanfil, 2013; Johnstone et al., 2010], while developing and underdeveloped countries' interest in RE is based upon facilitating the modernization of the energy sector, fostering energy sustainability, and supporting economic development goals [Kaygusuz et al., 2007; REN21, 2018]. For example, the use of RE is a solution to the challenges of African rural electrification [Inglesi-Lotz, 2013]. Addressing this need with RE has important implications for raising Africa's standard of living but would also act as a driver for increased economic development.

With countries having disparate motivation and goals with respect to RE development, a fair question to ask is whether the interplay between RE and economic development is consistent across countries despite these differences. One way to shed light on this question is to select a case study set of countries with vast differences in economic development, energy resources, and policies with regard to RE. The countries of the United Kingdom (UK), Turkey, and Nigeria represent such a set. These countries were selected because they are diverse and unlike many countries, the required data is available. Their main characteristics are provided at the Table 1.

Numerous studies have explored the relationship between economic growth and total energy consumption and found a positive correlation [Payne, 2010; Halicioglu, 2009; Bowden, Payne, 2010; Huang et al., 2008]. For the case study countries, this finding has been replicated in the UK [Humphrey, Stanislaw, 1979; Lee, Chien, 2010], Turkey [Ocal, Aslan, 2013], and Nigeria [Ighodaro, 2010; Akinlo, 2009]. Less research has been conducted on the more specific relationship between economic growth and RE development [Apergis, Payne, 2010, 2014; Menyah, Wolde-Rufael, 2010; Sadorsky, 2009a], and to date, no empirical study has been conducted on this relationship in the UK, Turkey, and Nigeria.

The goal of this study was to take a unique approach, compared to previous studies, in order to scrutinize the link between RE consumption (electricity from renewables) and economic development within the case study countries. The present study describes the electricity market in the case study countries with an analysis of power generation using a range of different renewable energy sources. This study will use a standard VAR model to focus on RE consumption, income, and electricity prices and how they may interact with one another. Moreover, this VAR model will reveal any dynamic interactions between these variables and allow for the construction of forecasts that will predict the future of the relationship between $\mathrm{RE}$ and economic development through 2030. A finding that a change in economic growth has a significant impact upon RE consumption is consistent with the work of others [Apergis, Payne, 2010; 2014; Menegaki, 2011; Sadorsky, 2009a, 2011]. However, this study is different because these previous studies used panel VAR techniques and only did so to argue that there is a relationship between RE consumption and other variables such as carbon dioxide (CO2) emissions, oil prices, and gross domestic product (GDP). This study's use of a diverse group of countries, a longer time span of data than used previously [Menegaki, 2011; Ohler, Fetters, 2014], and a more recently collected data set offers an opportunity to discover new and important insights into the interplay between RE consumption and economic development. To my knowledge, this approach, using this kind of analysis, with these particular variables, over such a long period of time, and on this unique set of countries has never been attempted.

\section{Review of the Existing Literature}

The Vector Autoregression (VAR) model approach has been used with success to examine the relationship between RE consumption and variables related to economic development [Apergis, Payne, 2010, 2014; Menegaki, 2011; Sadorsky, 2009a, 2011; Ohler, Fetters, 2014]. Sadorsky [Sadorsky, 2011] used the VAR model to analyze the relationship among RE consumption, income, oil prices, and oil consumption over the period from 1980 to 2008. He suggested that positive shocks to income increase RE consumption. Sadorsky [Sadorsky, 2009a] employs a VAR approach to analyze the relationships among RE consumption, income, oil prices, and CO2 emissions in the G7 countries over the period 1980-2005 by performing panel unit root and cointegration tests. He pointed out that increases in income and $\mathrm{CO} 2$ emissions are the major drivers for increases in RE consumption in the long run. Silva et al. [Silva et al., 2012] analyzed how an increasing share of RE sources in power generation affects economic growth and carbon emissions using structural VAR approach over the period 1960 to 2004 for Denmark, Portugal, Spain, and the United States. Their findings show that economic costs emerged with the increase of RE in terms of GDP per capita and the decrease of $\mathrm{CO} 2$ emissions per capita was ensured.

Several studies have looked at the relationship between RE consumption and different macroeconomic variables (e.g., income, oil prices, capital, labor) at the country or regional level [Sadorsky, 2009b, 2011; Salim, Rafiq, 2012; Vaona, 2012]. The consensus from these studies is that increases in income are positively related to increased RE consumption. This makes sense given that RE prices may be higher 
Table 1. Basic Characteristics of the Case Study Countries

\begin{tabular}{|l|l|l|l|}
\hline \multicolumn{1}{|c|}{ Parameters } & \multicolumn{1}{c|}{ UK } & \multicolumn{1}{c|}{ Turkey } & \multicolumn{1}{c|}{ Nigeria } \\
\hline State of economy & Developed & Developing & Underdeveloped \\
\hline $\begin{array}{l}\text { Geographic position (global } \\
\text { region) }\end{array}$ & Europe & Asia & Africa \\
\hline Territory $\left(\mathrm{km}^{2}\right)$ & 242,495 & 783,562 & 923,768 \\
\hline Climate & $\begin{array}{l}\text { Temperate maritime (it is mild with } \\
\text { temperatures not much lower than 0 } \\
\text { in winter and not much higher than } \\
32^{\circ} \mathrm{C} \text { in summer) }\end{array}$ & $\begin{array}{l}\text { Hot summer Mediterranean (It is } \\
\text { hot with dry summers and mild to } \\
\text { cool, wet winters) }\end{array}$ & Tropical \\
\hline GDP growth in 2013 (\%) & 1.9 & 3.6 & 7.7 \\
\hline Rise of RE consumption $(\%)^{*}$ & 19 & 19.3 & 1.97 \\
\hline $\begin{array}{l}\text { Target share of RE in energy } \\
\text { production }\end{array}$ & $20 \%$ by 2020 & $30 \%$ by 2030 & $10 \%$ by 2025 \\
\hline
\end{tabular}

Note: ${ }^{*}$ For the UK, data from 2011 are provided; for Turkey and Nigeria, data from 2012 . By comparison, the global growth rate of RE sources was $4.4 \%$ in the first decade of the 21 st century worldwide.

Source: compiled by the author based on [IRENA, 2018a; World Bank, 2013; Pao, Fu, 2013; Ward, Inderwildi, 2013; Melikoglu, 2013; Yusuf, 2014].

than energy derived from fossil fuels in some circumstances and people need to be able to afford RE to use it. Sadorsky [Sadorsky, 2009b] presented two empirical models of RE consumption and income for 18 emerging countries with panel VAR over the period 1994 to 2003. First empirical model assessed the relationship between $\mathrm{RE}$ consumption and income, and the results show that increases in income have a positive impact upon RE consumption. The second model examined the relationships among RE consumption, income, and electricity prices. This result suggested that RE consumption is more sensitive to RE price changes than overall electricity demand.

Apergis and Payne [Apergis, Payne, 2010] used panel VAR techniques to analyze the relationship between RE consumption and economic growth for a panel of 20 OECD countries over the period 1985-2005. The theoretical framework uses an aggregate production function relating output to labor, capital, and RE. They found evidence of bidirectional causality between RE consumption and economic growth in both the short and long run. Salim and Rafiq [Salim, Rafiq, 2012] analyzed the determinants (income, pollutant emission, and oil prices) on RE consumption for six developing countries (Brazil, China, India, Indonesia, Philippines, and Turkey) by using both panel data and time series analyses covering the period 1980 to 2006. Their results suggest that there are bidirectional causal links between RE and income and between $\mathrm{RE}$ and pollutant emission. These outcomes indicate that in the long run, RE consumption is significantly determined by income, while oil prices seem to have less of a negative impact upon RE consumption in these countries. More recently, Ohler and Fetters [Ohler, Fetters, 2014] studied the causal relationship between economic growth and electricity generation from renewable sources across 20 OECD countries over the period of 1990 to 2008. They found evidence of a bidirectional short-run relationship between aggregate renewable electricity generation and GDP. Apergis and Payne [Apergis, Payne, 2014] observed Central American countries from 1980 to 2006 using the panel VAR approach. ${ }^{1}$ Their results suggest evidence of bidirectional causality between RE consumption and economic growth in the long run.

In contrast to bidirectional results, some papers reported a unidirectional relationship between RE consumption and economic growth. Vaona [Vaona, 2012] by using Granger non-causality tests [Granger, 1980] found unidirectional Granger causality from RE consumption to real GDP for Italy. ${ }^{2}$ Payne [Payne, 2011] investigated the relationship between biomass consumption and GDP in the US and found a positive unidirectional relationship from biomass to GDP. Menyah and Wolde-Rufael [Menyah, WoldeRufael, 2010] studied the relationships between RE consumption, CO2 emissions, nuclear consumption, and real GDP for the United States over the period 1960-2007 using the VAR model. They reported that there are unidirectional causality relations from nuclear energy consumption to $\mathrm{CO} 2$ emissions and from GDP to RE but no causality from RE consumption to CO2 emissions. Menegaki [Menegaki, 2011] studied the causal relationship between economic growth and RE for 27 European countries in a VAR panel context over the period 1997-2007. His outcomes did not confirm causality between RE consumption and GDP.

To summarize the literature review, there have been a great number of studies on the relationship between $\mathrm{RE}$ consumption and economic growth, but the current research lacks clear evidence on the direction of causality between these three variables in general and within case countries. Furthermore, existing research does not include data from the past three years, a period of notable RE growth that merits inclusion in forecasting models.

\footnotetext{
They define RE consumption as total renewable electricity consumption in millions of kilowatt-hours.

2 The author investigated RE consumption and income relationship with an annual frequency from 1861 to 2000.
} 
Table 2. Data sources

\begin{tabular}{|l|l|}
\hline \multicolumn{1}{|c|}{ Organization } & \multicolumn{1}{c|}{ Reference } \\
\hline World Bank & [World Bank, 2013] \\
\hline International Energy Agency (IEA) & https://www.iea.org/energyaccess/database/ \\
\hline Turkish Statistical Institute (TUIK) & http://www.turkstat.gov.tr/ \\
\hline United Kingdom Energy Research Centre (UKERC) & http://www.ukerc.ac.uk/ \\
\hline International Renewable Energy Agency (IRENA) & [IRENA, 2018b] \\
\hline US International Energy Statistics (EIA) & https://www.eia.gov/outlooks/ieo/ \\
\hline Source: compiled by the author. & \\
\hline
\end{tabular}

\section{Data and Methodology}

\section{Data}

Annual data for the UK, Turkey, and Nigeria from 1990 through 2012 was collected on RE consumption (ren), electricity price (ep), and income (gdp). Data sources are summarized in Table 2.

Data on RE consumption was derived from the IEA database and measured in billion kilowatt-hours. RE is the electricity generated from wind, solar, geothermal, biomass, hydropower, tidal, and wave sources. This paper uses electricity price, as opposed to oil price (the most pervasive energy source), because of the strong penetration of the RE sources and the fact that the electricity price has added significance in the energy balances of most countries [Silva et al., 2012].

GDP per capita comes from the World Bank database and is measured in current US dollars. It is an indicator of economic well being in a country. GDP is also taken as per capita due to the fact per capita variables ensure a better and less biased comparison among countries with differing population characteristics [Aqeel, Butt, 2001]. A key economic growth indicator, GDP was used as a proxy of income in the studies detailed above [Marques, Fuinhas, 2011; Sadorsky, 2009a]. In the literature, economic growth measured in terms of GDP (real or per capita), or growth rate of GDP, uses different econometric methodologies, countries, and time periods [Apergis, Payne, 2010; Bretschenger, 2010; Bruns, Gross, 2013; Chiou-Wei et al., 2008; Gross, 2012; Payne, Taylor, 2010]. For instance, Payne and Taylor [Payne, Taylor, 2010] found no Granger causality between energy consumption and real GDP. This is consistent with the findings of [Menyah, Wolde-Rufael, 2010; Chiou-Wei et al., 2008]. There is a long-run equilibrium relationship between real GDP and energy consumption [Apergis, Payne, 2010; Belke et al., 2011; Mohammadi, Parvaresh, 2014].

The electricity price variable was taken from the Turkish Statistical Institute (TUIK), United Kingdom Energy Research Centre (UKERC), and World Bank databases and it is reflected in the current fuel price index numbers $2005=100$ for this paper. This study analyzes an additional channel of causality by presenting electricity prices. Although electricity prices have been neglected in many previous studies (e.g., [Yildirim et al., 2012]), I examine electricity price as a proxy because of its effects on both energy consumption and economic growth. Furthermore, an increase in prices is anticipated to indicate a decline in energy demand, which leads to a decline in energy consumption [Odhiambo, 2010]. In other words, while energy demand represents the rate at which electricity is consumed, energy consumption represents the amount of electricity that has been consumed over a certain time.

RE consumption has been growing for the UK and Turkey but it is stable for Nigeria over the period (Figure 1a). GDP per capita has been growing along a linear trend line for all countries (1b). Electricity prices in all case study countries tend to move upward over time (1c). Figure 1 shows the heterogeneity of the historical data of the three countries. For instance, in Figure 1b, the trends are more like quadratic functions than linear. In Figure 1c, there is even an obvious drop in the UK in terms of electricity prices for a certain time period.

The selection of the variables for this study is based on comparability with the variables collected in previous research, so that the data collected on these variables in the more recent timeframe of this study can easily be compared with data collected earlier.

\section{Methodology}

The standard VAR technique was developed for the model estimation of the relationship between RE consumption and economic growth. The present study uses a standard VAR model to focus on RE consumption, income, and electricity prices and how they interact with one another. Moreover, this VAR model reveals any dynamic interactions between these variables and allows for the construction of forecasts that will predict the future of the relationship between RE and economic development through 2030. This approach is used because there is no need to made assumptions of exogeneity concerning which variables are response variables or explanatory variables since all variables in VAR are treated as endogenous, thus reflecting the realities of interdependence. This model ensures a much richer data structure that can capture complex dynamic properties of the data [Sadorsky, 2011; Taylor, 2010]. 
1a) REN (billion Watts per hour)

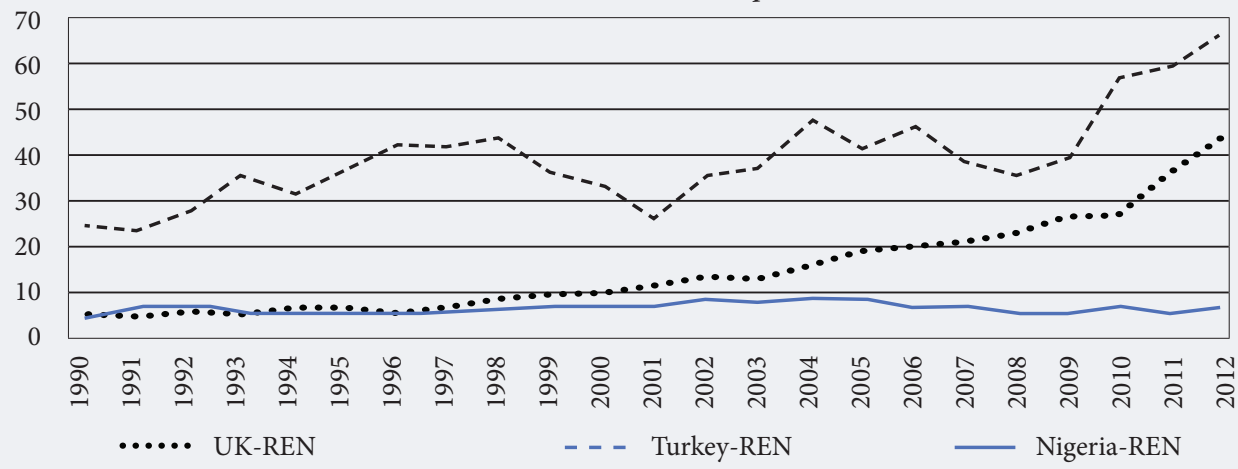

1b) GDP per capita (USD)

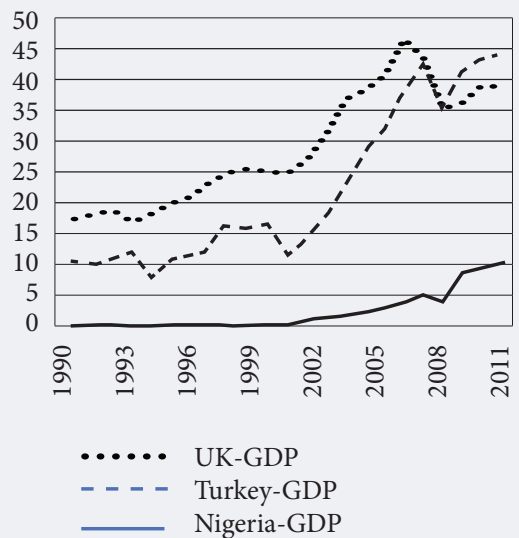

1c) REP (Consumer Price Index)

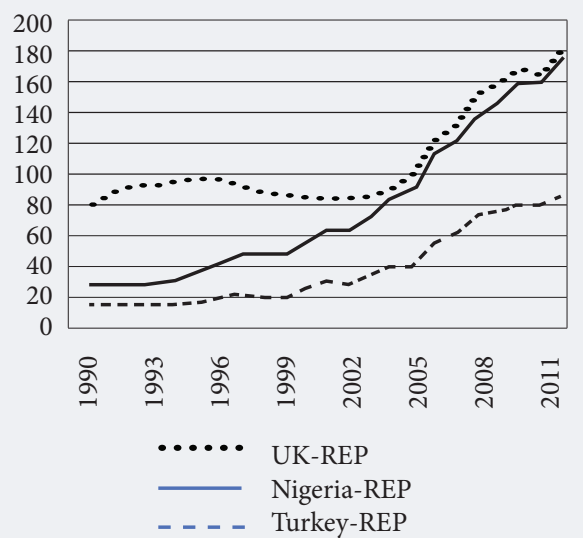

Source: author's calculations.

Moreover, the model is well suited to forecast the effects of specific policy actions or of significant changes in the economy [Tiwari, 2011]. For the Granger causality test, a VAR model was selected rather than a VECM model as the VECM model is only defined when the time-series are cointegrated. Finally, when this is the case, the series need to be integrated in the same order. Furthermore, a VAR model is preferred rather than using a VECM model for causality testing [Giles, 2011].

These features make VAR the ideal choice for analyzing the macroeconomic responses in the case countries to RE consumption. The standard VAR model is specified as:

$Y_{t}=\Gamma(\mathrm{L}) Y_{t-1}+\varepsilon_{t}$

where $Y_{t}$ is a vector of stationary variables $\{\Delta \mathrm{REN}, \Delta \mathrm{EP}, \Delta \mathrm{GDP}\}$ with $\Delta \mathrm{REN}=$ the first difference in renewable consumption; $\Delta \mathrm{GDP}=$ economic growth as per capita; $\Delta \mathrm{EP}=$ the change in electricity prices, and $\varepsilon_{t}=$ the vector of error terms. $\Gamma(\mathrm{L})$ is the lag operator which is calculated below.

$\Gamma(\mathrm{L})=\Gamma_{1} L^{1}+\Gamma_{2} L^{2}+\cdots+\Gamma_{p} L^{p}$

The model also makes provisions for error terms and shocks to calculate the impulse response functions (IRF) and the forecast error variance decompositions (FEVD). IRF and FEVD show the dynamic responses and size of the total effect, respectively. The estimation of interaction between RE consumption, economic growth, and electricity price are based on the IRFs and the FEVDs after estimating the VAR model. The IRFs usually show the effects of shocks on the adjustment path of the variables. The FEVDs measure the contribution of each type of shock to forecast error variance. Both computations are effective in determining how shocks to economic variables reverberate through a system [Phillips, 1998].

The IRFs are based on the Cholesky decomposition approach. The Cholesky decomposition strategy entails a contemporaneous relationship among the variables. The first variable in the VAR system influences the other variables contemporaneously, while the following variables in the VAR impact the variables listed earlier only in their lag form [Aziz, Dahalan, 2015]. Considering that the variables correspond to the Cholesky decomposition, the order (ren; $g d p ; e p)$ is then imposed from the most to the least exogenous. 
Table 3. Summary Statistics over 1990-2012 for Variables

\begin{tabular}{|c|c|c|c|c|c|c|c|c|c|}
\hline & uk_ren & uk_gdp & uk_ep & t_ren & t_gdp & t_ep & n_ren & n_gdp & n_ep \\
\hline Mean & 15.45759 & 29293.26 & 108.8696 & 37.72006 & 5532.397 & 97.61371 & 6.039212 & 781.5134 & 71.96087 \\
\hline Median & 12.02800 & 25870.99 & 92.80000 & 35.49400 & 4219.544 & 74.11461 & 5.850000 & 377.5003 & 57.30000 \\
\hline Maximum & 43.82253 & 46610.53 & 181.4000 & 64.37187 & 10666.06 & 206.0910 & 8.152000 & 2722.298 & 178.9000 \\
\hline Minimum & 5.321000 & 17270.12 & 80.20000 & 22.57500 & 2268.397 & 46.70890 & 4.343000 & 153.0762 & 3.930000 \\
\hline Std. Dev. & 10.47715 & 9311.265 & 31.56791 & 10.63177 & 3028.173 & 55.77279 & 0.965901 & 766.0461 & 55.36502 \\
\hline Skewness & 1.180469 & 0.284903 & 1.104866 & 0.840289 & 0.650318 & 0.793446 & 0.746967 & 1.519842 & 0.506311 \\
\hline Kurtosis & 3.690039 & 1.695320 & 2.676368 & 3.428594 & 1.795478 & 2.034864 & 3.321090 & 4.071345 & 2.035646 \\
\hline Jarque-Bera & 5.798087 & 1.942417 & 4.779835 & 2.882703 & 3.011588 & 3.305975 & 2.237647 & 9.954652 & 1.873909 \\
\hline Probability & 0.055076 & 0.378625 & 0.091637 & 0.236608 & 0.221841 & 0.191477 & 0.326664 & 0.006892 & 0.391819 \\
\hline Sum & 355.5245 & 673745.1 & 2504.000 & 867.5614 & 127245.1 & 2245.115 & 138.9019 & 17974.81 & 1655.100 \\
\hline Sum Sq. Dev. & 2414.957 & $1.91 \mathrm{e}+09$ & 21923.73 & 2486.758 & $2.02 \mathrm{e}+08$ & 68433.29 & 20.52523 & 12910187 & 67436.28 \\
\hline Observations & 23 & 23 & 23 & 23 & 23 & 23 & 23 & 23 & 23 \\
\hline
\end{tabular}

The lag-length for the model is selected using the Akaike Information Criteria (AIC) [Akaike, 1974] because of its better performance in small samples [Ozturk, Acaravci, 2013]. This study carried out the stationarity and cointegration tests, as well as the Granger causality tests, for all variables. Finally, this paper also implemented the prediction model which was developed by using a time series forecasting system and evaluated using the VAR method to construct a dynamic forecast over the period 2013-2030 for the UK, Turkey, and Nigeria. E-views and Stata were used in this study to analyze these variables.

\section{Summary Statistics}

Table 3 below shows the summary statistics for the variables in the case study countries.

The following diagnostic tests were carried out to analyze and understand the characteristics of the variables. First, the lag selection was carried out. Second, the test for stationarity was conducted by applying several diagnostic tests to check if the series contained unit roots (non-stationary series) or not (stationary series). Third, the cointegration properties of the variables were checked. Then, the study indicates the nature of causality for the variables of interest.

\section{Lag Selection}

To reliably check for co-integration, it is crucial to determine the suitable lag length. According to [Kireyev, 2000], excessively short lags may fail to capture the system's dynamics leading to the omission of

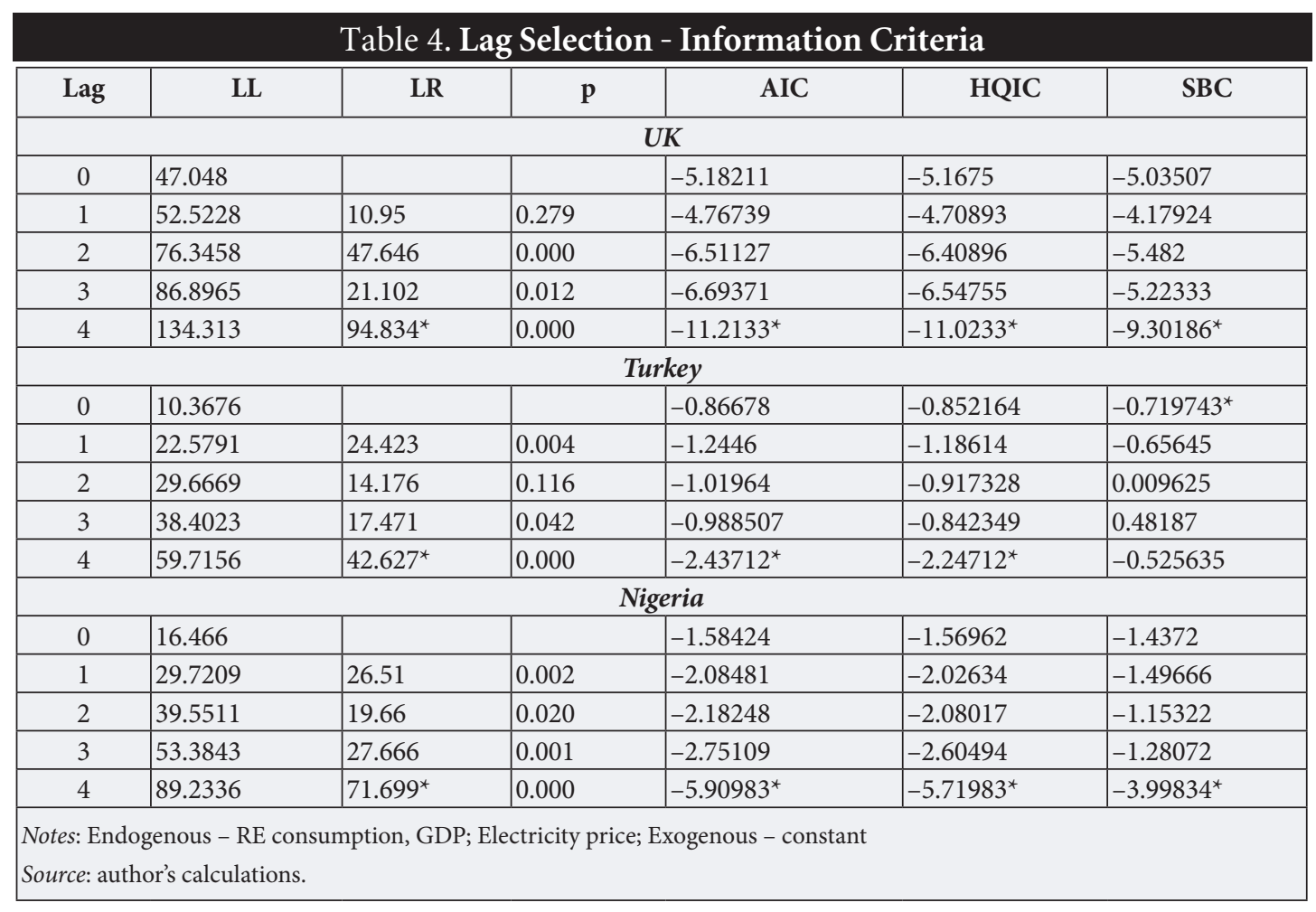


Table 5. Unit Root Test for the Series in Levels

\begin{tabular}{|c|c|c|c|c|c|c|c|c|c|c|c|c|c|}
\hline \multirow{3}{*}{ Data } & \multicolumn{6}{|c|}{ ADF-test } & \multirow{3}{*}{ Data } & \multicolumn{6}{|c|}{ PP-test } \\
\hline & \multicolumn{3}{|c|}{ Intercept and no trend } & \multicolumn{3}{|c|}{ Intercept and trend } & & \multicolumn{3}{|c|}{ Intercept and no trend } & \multicolumn{3}{|c|}{ Intercept and trend } \\
\hline & lags & t-stat & \%5 level ${ }^{\star}$ & lags & t-stat & $\% 5$ level $^{*}$ & & lags & t-stat & $\% 5$ level $^{\star}$ & lags & t-stat & $\% 5$ level $^{*}$ \\
\hline ren_uk & 2 & 1.82 & -3.02 & 3 & -1.38 & -3.67 & ren_uk & 21 & 4.71 & -3.00 & 6 & -2.56 & -3.63 \\
\hline ren_t & 3 & -0.74 & -3.02 & 2 & -3.64 & -3.65 & ren_t & 2 & -1.40 & -3.00 & 2 & -2.34 & -3.63 \\
\hline ren_n & 3 & -2.29 & -3.02 & 3 & -2.77 & -3.67 & ren_n & 2 & -3.22 & -3.00 & 2 & -3.06 & -3.63 \\
\hline Gdp_uk & 4 & -0.76 & -3.04 & 3 & -2.86 & -3.67 & Gdp_uk & 1 & -1.00 & -3.00 & 0 & -1.46 & -3.63 \\
\hline Gdp_t & 0 & -0.34 & -3.00 & 0 & -2.55 & -3.63 & Gdp_t & 0 & -0.34 & -3.00 & 0 & -2.55 & -3.63 \\
\hline Gdp_n & 3 & 1.34 & -3.02 & 4 & -0.90 & -3.69 & Gdp_n & 3 & 1.07 & -3.00 & 10 & -2.96 & -3.63 \\
\hline Ep_uk & 1 & 0.32 & -3.01 & 1 & -1.30 & -3.64 & Ep_uk & 2 & 0.44 & -3.00 & 2 & -0.71 & -3.63 \\
\hline Ep_t & 0 & 0.75 & -3.00 & 0 & -2.39 & -3.63 & Ep_t & 2 & 0.88 & -3.00 & 4 & -2.42 & -3.63 \\
\hline Ep_n & 4 & -2.91 & -3.04 & 1 & -4.97 & -3.64 & Ep_n & 1 & -3.59 & -3.00 & 1 & -1.62 & -3.63 \\
\hline
\end{tabular}

Note: ${ }^{\star}$ - indicates the level of significance at $5 \%$ (5\% level of critical value) and Lag length selected using Akaike's information criterion which is given in the first column.

Source: author's calculations

variables, coefficients' bias, and serial correlation-based errors, whilst lag lengths that are excessively long cause a rapid loss of the degree of freedom and over-parameterization. In other words, the estimation of the appropriate lag prevents the over-parameterization of the model. The Akaike Information Criterion (AIC), the Hannan Quinn Information Criterion (HQIC) [Hannan, Quinn, 1979], and the Schwarz Bayesian Criterion (SBC) [Schwarz, 1978] were used for this purpose. The information criteria suggest that the appropriate lag length that should be used to test for co-integration is VAR=4, which was used for the evaluation of VAR. The lag-length selection table is presented in Table 4 below.

\section{Stationary Properties}

The autocorrelation function (ACF) and partial autocorrelation function (PACF) demonstrate that the variables (RE consumption, economic growth, and electricity price) are non-stationary. For this study, formal stationarity tests were carried out through unit root tests. The unit root tests included a constant, time trend, and four lags in line with the general and specific stationarity analysis. At the level of dynamic series, the null hypotheses that the variables are non-stationary are not rejected, indicating non-stationarity for all the variables.

To identify the order of the integration of the series, a unit root test [Ng, Perron, 2001] was employed with Augmented Dickey Fuller (ADF) [Dickey, Fuller, 1981] and Phillips and Perron (PP) [Phillips, Perron, 1988] tests. Then, a cointegration analysis was conducted in order to identify the nature of the cointegration [Abbott, De Vita, 2003]. Diagnostic tests for the existence of stationarity are crucial as the two categories of the series are treated in different ways [Brooks, 2008] and the non-stationary does not have a constant mean and there is the emergence of heteroscedasticity [Enders, 1995]. The ADF and PP unit root tests imply that all series are stationary, in other words, they are all integrated by order 0 , that

\section{Table 6. Unit Root Test for the Series in the First Difference (1st difference of the values)}

\begin{tabular}{|c|c|c|c|c|c|c|c|c|c|c|c|c|c|}
\hline \multirow{3}{*}{ Data } & \multicolumn{6}{|c|}{ ADF-test } & \multirow{3}{*}{ Data } & \multicolumn{6}{|c|}{ Tест PP-test } \\
\hline & \multicolumn{3}{|c|}{ Intercept and no trend } & \multicolumn{3}{|c|}{ Intercept and trend } & & \multicolumn{3}{|c|}{ Intercept and no trend } & \multicolumn{3}{|c|}{ Intercept and trend } \\
\hline & lags & t-stat & \%5 level ${ }^{\star}$ & lags & t-stat & $\% 5$ level $^{*}$ & & lags & t-stat & $\% 5$ level $^{*}$ & lags & t-stat & $\% 5$ level $^{*}$ \\
\hline ren_uk & 1 & -3.94 & -3.02 & 1 & -4.81 & -3.65 & ren_uk & 10 & -6.62 & -3.01 & 20 & -14.94 & -3.64 \\
\hline ren_t & 2 & -3.62 & -3.02 & 2 & -3.49 & -3.67 & ren_t & 1 & -4.83 & -3.01 & 1 & -4.71 & -3.64 \\
\hline ren_n & 3 & -2.19 & -3.04 & 0 & -6.25 & -3.64 & ren_n & 0 & -6.48 & -3.01 & 0 & -6.25 & -3.64 \\
\hline Gdp_uk & 3 & -2.60 & -3.04 & 3 & -2.55 & -3.69 & Gdp_uk & 5 & -3.18 & -3.01 & 6 & -3.08 & -3.63 \\
\hline Gdp_t & 0 & -5.31 & -3.01 & 0 & -5.23 & -3.64 & Gdp_t & 0 & -5.31 & -3.01 & 0 & -5.23 & -3.64 \\
\hline Gdp_n & 0 & -5.00 & -3.01 & 3 & -4.96 & -3.69 & Gdp_n & 3 & -5.15 & -3.01 & 14 & -9.74 & -3.64 \\
\hline Ep_uk & 0 & -2.28 & -3.01 & 3 & -2.60 & -3.64 & Ep_uk & 1 & -2.26 & -3.01 & 1 & -2.84 & -3.64 \\
\hline Ep_t & 0 & -4.49 & -3.01 & 0 & -4.76 & -3.64 & Ep_t & 1 & -4.49 & -3.01 & 3 & -4.80 & -3.64 \\
\hline Ep_n & 0 & -1.64 & -3.01 & 1 & -2.45 & -3.65 & Ep_n & 1 & -1.80 & -3.01 & 2 & -3.00 & -3.64 \\
\hline \multicolumn{14}{|c|}{$\begin{array}{l}\text { Note: }{ }^{*} \text { - indicates the level of significance at } 5 \% \text { ( } 5 \% \text { level of critical value) and Lag length selected using Akaike's information criterion which is given in } \\
\text { the first column. }\end{array}$} \\
\hline
\end{tabular}


Table 7. Unit Root Test for the Series in the Second Difference (2st difference of the values)

\begin{tabular}{|c|c|c|c|c|c|c|c|c|c|c|c|c|c|}
\hline \multirow{3}{*}{ Data } & \multicolumn{6}{|c|}{ ADF-test } & \multirow{3}{*}{ Data } & \multicolumn{6}{|c|}{ Tест PP-test } \\
\hline & \multicolumn{3}{|c|}{ Intercept and no trend } & \multicolumn{3}{|c|}{ Intercept and trend } & & \multicolumn{3}{|c|}{ Intercept and no trend } & \multicolumn{3}{|c|}{ Intercept and trend } \\
\hline & lags & t-stat & $\% 5$ level $^{*}$ & lags & t-stat & $\% 5$ level $^{*}$ & & lags & t-stat & $\% 5$ level $^{*}$ & lags & t-stat & $\% 5$ level $^{*}$ \\
\hline ren_uk & 2 & -5.06 & -3.85 & 2 & -4.94 & -3.69 & ren_uk & 8 & -14.95 & \begin{tabular}{|l|}
-3.02 \\
\end{tabular} & 8 & -14.82 & -3.65 \\
\hline ren_t & 0 & -8.83 & -3.02 & 4 & -3.47 & -3.73 & ren_t & 3 & -10.35 & -3.02 & 3 & -10.24 & -3.65 \\
\hline ren_n & 1 & -6.90 & -3.02 & 1 & -6.73 & -3.67 & ren_n & 19 & -22.69 & -3.02 & 19 & -26.01 & -3.65 \\
\hline Gdp_uk & 1 & -6.09 & -3.02 & 1 & -6.01 & -3.67 & Gdp_uk & 14 & -9.02 & -3.02 & 14 & -9.08 & -3.65 \\
\hline Gdp_t & 0 & -8.53 & -3.02 & 0 & -8.30 & -3.65 & Gdp_t & 9 & -16.80 & -3.02 & 10 & 17.68 & -3.65 \\
\hline Gdp_n & 4 & -4.25 & -3.06 & 3 & -4.49 & -3.71 & Gdp_n & 17 & -19.87 & -3.02 & 15 & 23.37 & -3.65 \\
\hline Ep_uk & 0 & -5.59 & -3.02 & 0 & -5.53 & -3.65 & Ep_uk & 1 & -5.63 & -3.02 & 0 & -5.53 & -3.65 \\
\hline Ep_t & 2 & -4.50 & -3.04 & 2 & -4.86 & -3.69 & Ep_t & 11 & -14.40 & -3.02 & 9 & 15.99 & -3.65 \\
\hline Ep_n & 0 & -4.46 & -3.02 & 0 & -4.20 & -3.65 & Ep_n & 3 & -4.66 & -3.02 & 5 & -5.01 & -3.65 \\
\hline
\end{tabular}

is I(0). The characteristics of the dynamic series (levels) and the first difference were evaluated with the help of two different unit root tests, namely ADF and PP. This present study provides some results that depend upon the test used (ADF or PP) and upon the trend specification.

The unit root tests included the constant, time trend, and four lags in line with the general and specific stationarity analysis methodology. As Perron [Perron, 1988] notes, the hypothesis of a unit root with a trend are usually precluded a priori, for instance, if the series is in logarithmic form, it implies an ever increasing (or decreasing) rate of change. Regarding the dynamic series (levels), the null hypotheses that the variables are non-stationary are not rejected. It can be seen that the test statistic is less negative than the critical values at a 5\% level of significance for each series and as a result, do not reject H0 since all the variables are non-stationary. The results are displayed in Table 5. After taking first differences, each of the time series appears to contain a unit root in their levels but almost all series are stationary in their first difference indicating that they are integrated at order one, i.e., I(1). The results are displayed in Table 6 which indicates that the second ADF test of the first difference shows that most series are stationary having more negative test statistics than the applicable critical values. RE price in the UK and Nigeria are not stationary after the first differences. The series became stationary by taking the second difference of the values indicating that they are integrated at I(2). Table 7 displays the results from the ADF and PP test and it can be seen that the critical values of a $5 \%$ level of significance is less negative than the test statistic for each series and as a result, $\mathrm{H}(0)$ is rejected because all the variables are stationary.

\section{Cointegration Analysis}

This study applied the necessary cointegration analysis after the stationarity tests above. The outcome of the trace test $(\lambda \max )$ along with that of the eigenvalue test indicates the long-run relationship between $\mathrm{RE}$ consumption and the two other variables (economic growth and electricity price) for each country. The present study rejects the null hypothesis of no cointegration on behalf of the alternative hypothesis that there is at least one cointegration relationship at the five percent (5\%) significance level for Nigeria. The result of the cointegration tests meets the a priori assumption of the stationarity of the variables. The present study enables all the variables to be included in the VAR model in their level forms with the introduction of the lags where necessary. This approach avoids the loss of significant information from the time-series co-movements of the variables [Kireyev, 2000]. The outcome of the cointegration test is presented in Table 8 below.

It is widely known that cointegration tests depending on the individual time series have low statistical power, especially when the time series is short [Belke et al., 2011]. Cointegration between the variables can be examined by employing time series tests such as the Johansen's maximum likelihood approach. The hypotheses for this test are the following: the null hypothesis $\left(\mathrm{H}_{0}\right)$ states that there are $\mathrm{r}$ cointegrating vectors, whereas the alternative hypothesis $\left(\mathrm{H}_{1}\right)$ illustrates that there are $\mathrm{r}+1$ or more [Brooks, 2008]. Given that the unit root test showed that the variables are non-stationary in their levels and differenced forms, the result of the cointegration tests satisfies the a priori assumptions of the stationarity of the variables.

\section{Empirical Results and Discussions}

All variables were expressed in natural logarithms for estimating the VAR [Ewing et al., 2007; Narayan, Prasad, 2008; Sadorsky, 2009a] and logarithmical differences were used because this guarantees all 
Table 8. Johansen Tests for Cointegration (Trend: constant, Lags=4)

\begin{tabular}{|c|c|c|c|c|c|c|}
\hline Max rank & Parms & LL & Eigenvalue & $\begin{array}{l}\text { trace statistic } \\
(\lambda \max )\end{array}$ & $\begin{array}{l}5 \% \text { critical } \\
\text { value }\end{array}$ & $1 \%$ critical value \\
\hline \multicolumn{7}{|c|}{ UK } \\
\hline 0 & 30 & 76.281248 & & 116.0644 & 29.68 & 35.65 \\
\hline 1 & 35 & 112.98909 & 0.98668 & 42.6487 & 15.41 & 20.04 \\
\hline 2 & 38 & 130.95271 & 0.87917 & 6.7215 & 3.76 & 6.65 \\
\hline 3 & 39 & 134.31347 & 0.32658 & & & \\
\hline \multicolumn{7}{|c|}{ Turkey } \\
\hline 0 & 30 & 30.406466 & & 58.6182 & 29.68 & 35.65 \\
\hline 1 & 35 & 45.425247 & 0.82914 & 28.5806 & 15.41 & 20.04 \\
\hline 2 & 38 & 56.132362 & 0.71625 & 7.1664 & 3.76 & 6.65 \\
\hline 3 & 39 & 59.715562 & 0.34397 & & & \\
\hline \multicolumn{7}{|c|}{ Nigeria } \\
\hline 0 & 30 & 51.050487 & & 76.3662 & 29.68 & 35.65 \\
\hline 1 & 35 & 83.416096 & 0.97780 & $11.6350^{*}, * *$ & 15.41 & 20.04 \\
\hline 2 & 38 & 87.338587 & 0.36964 & 3.7900 & 3.76 & 6.65 \\
\hline 3 & 39 & 89.233586 & 0.19984 & & & \\
\hline \multicolumn{7}{|c|}{$\begin{array}{l}\text { Note: Presence of cointegration relationship: }{ }^{*}-\text { significant at } 1 \% \text { level; }{ }^{* *}-\text { significant at } 5 \% \text { level. } \\
\text { Source: author's calculations. }\end{array}$} \\
\hline
\end{tabular}

variables are stationary. VAR estimation strategies, which require the model identification by using the stationarity test, lag selection, causal ordering, and restrictions for measuring the impulse response functions and forecast error variance decomposition are presented below. Finally, a prediction model was developed for the years 2013-2030 for each country. Therefore, this section includes the impulse response function, variance decomposition from the VAR, and the prediction model.

\section{Impulse Response Function Analysis}

The analyses examined the relationship between RE consumption, economic growth, and electricity price using the IRF methodology. Impulse response functions are only valid if the VAR is stable. Therefore, some steps must be taken to ensure that the VAR is stable while the IRFs are used to interpret the results [Sadorsky, 2011]. The IRF indicates how a residual shock to one of the innovations in the model influences the contemporaneous and future values of all endogenous variables [Silva et al., 2012]. Significance was determined at the $95 \%$ confidence intervals. The error bands were gained by using a Monte Carlo simulation approach with 1,000 replications. According to the confidence intervals of the hypothesis, which were selected for the evaluation of the importance of the impulse response, standard errors were calculated. The IRF indicates how long, and to what extent, RE consumption reacts to an unanticipated change in income or electricity price [Lee, Chiu, 2011].

The IRF table presented in Table 9 shows that RE consumption in the case study countries responded negatively and significantly to a $10 \%$ deviation in economic growth by $0.2 \%$ (negatively) in the short run and, $0.06 \%$ (positively) in the long run. This indicates that income shocks among other variables affect the case study countries' RE consumption within the period under consideration. This means that economic growth in the sample countries respond positively and significantly to RE consumption shocks. Furthermore, RE consumption in the case study countries responded positively and significantly to a $10 \%$ change in prices by $0.09 \%$ in the short run and $0.05 \%$ (negatively) in the long run. The graphical representation of the predicted cointegrated plots for the sample countries are displayed in Figures 2, 3, and 4 .

This study's findings regarding RE consumption and economic growth are consistent with the empirical results of [Apergis, Payne, 2014, 2010; Tugcu et al., 2012] who found a relationship between RE consumption and income, and they concluded that the Granger causality function was more effective in explaining this relationship in the long run. In contrast, Menegaki's [Menegaki, 2011] empirical results attained using an identical approach did not confirm Granger causality between RE consumption and income.

\section{Variance Decomposition}

This study's analyses applied the advanced generalized forecast error variance decomposition to investigate the relationships between RE consumption, income, and electricity price, as well as to gauge the influences of the variables upon one another in the short and long run.

The variance decomposition reports are presented below in Table 10. The variance decomposition indicates that in the short run, approximately $1.3 \%$ of the fluctuations in case study countries' economic growth are explained by a $39 \%$ deviation in RE consumption shock. In the long run, in this case, ten years, a 
Table 9. Impulse Response Function Table

\begin{tabular}{|c|c|c|c|c|c|c|}
\hline \multirow{2}{*}{ Lag } & \multicolumn{3}{|c|}{ RE consumption response to GDP impulse } & \multicolumn{3}{|c|}{ GDP response to RE consumption impulse } \\
\hline & IRF & Lower $^{*}$ & Upper* & IRF & \begin{tabular}{|l} 
Lower $^{*}$ \\
\end{tabular} & Upper ${ }^{*}$ \\
\hline 0 & 0 & 0 & 0 & 0.129837 & 0.041622 & 0.218052 \\
\hline 1 & -0.021632 & -0.063027 & 0.019763 & -0.155564 & -0.270597 & -0.040532 \\
\hline 2 & 0.040584 & -0.014034 & 0.095201 & 0.013535 & -0.107074 & 0.134145 \\
\hline 3 & -0.025187 & -0.078152 & 0.027778 & 0.070993 & -0.063262 & 0.205248 \\
\hline 4 & 0.00415 & -0.042702 & 0.051002 & -0.056148 & -0.180937 & 0.06864 \\
\hline 5 & 0.009342 & -0.03387 & 0.052554 & 0.025267 & \begin{tabular}{|l|}
-0.059429 \\
\end{tabular} & 0.109963 \\
\hline 6 & -0.016782 & -0.053222 & 0.019658 & 0.00568 & -0.082561 & 0.093922 \\
\hline 7 & 0.012847 & -0.018325 & 0.044018 & -0.026774 & -0.10865 & 0.055103 \\
\hline 8 & -0.001571 & -0.028398 & 0.025256 & 0.020374 & -0.037378 & 0.078126 \\
\hline 9 & -0.006052 & -0.029513 & 0.017408 & \begin{tabular}{|l|}
-0.002498 \\
\end{tabular} & \begin{tabular}{|l|}
-0.044919 \\
\end{tabular} & 0.039924 \\
\hline 10 & 0.00697 & -0.012225 & 0.026164 & -0.00701 & -0.053275 & 0.039256 \\
\hline \multirow{2}{*}{ Lag } & \multicolumn{3}{|c|}{ RE consumption response to price impulse } & \multicolumn{3}{|c|}{ Price response to RE consumption impulse } \\
\hline & IRF & Lower $^{*}$ & Upper* & IRF & Lower $^{*}$ & Upper ${ }^{*}$ \\
\hline 0 & 0 & 0 & 0 & 0.000646 & -0.030654 & 0.031946 \\
\hline 1 & 0.00973 & -0.041043 & 0.060504 & -0.034834 & -0.064462 & -0.005206 \\
\hline 2 & -0.03622 & -0.106353 & 0.033914 & 0.011393 & -0.018633 & 0.041418 \\
\hline 3 & 0.024402 & -0.027108 & 0.075913 & 0.017364 & -0.013523 & 0.048251 \\
\hline 4 & 0.004931 & -0.030296 & 0.040159 & -0.009334 & -0.033847 & 0.01518 \\
\hline 5 & -0.016644 & -0.051474 & 0.018186 & 0.000057 & -0.020569 & 0.020683 \\
\hline 6 & \begin{tabular}{|l|}
0.014873 \\
\end{tabular} & -0.021251 & 0.050998 & 0.000853 & \begin{tabular}{|l|}
-0.016769 \\
\end{tabular} & 0.018474 \\
\hline 7 & -0.006975 & -0.034516 & 0.020566 & -0.003537 & -0.01881 & 0.011736 \\
\hline 8 & -0.003459 & -0.02586 & 0.018943 & 0.003204 & -0.007783 & 0.014191 \\
\hline 9 & 0.008274 & -0.013356 & 0.029905 & 0.000627 & \begin{tabular}{|l|}
-0.007485 \\
\end{tabular} & 0.008739 \\
\hline 10 & -0.00557 & -0.022887 & 0.011747 & -0.001856 & -0.009575 & 0.005863 \\
\hline
\end{tabular}

$100 \%$ deviation in RE consumption shocks accounts for about $7 \%$ of the fluctuations in economic growth in the case study countries. Furthermore, $0.2 \%$ of the fluctuations in electricity prices are explained by a $2 \%$ deviation in RE consumption shock in the short run and a $100 \%$ deviation for about $5.6 \%$ of the fluctuations in electricity prices in the long run.

As a result, economic growth significantly affects RE consumption in the sample countries both in the short and long run. Likewise, electricity prices in the countries are found to have significant effects upon $\mathrm{RE}$ consumption during the period under consideration. This result is in line with a priori expectations. This outcome is also consistent with the literature on the relationship between economic growth and RE consumption [Apergis, Payne, 2014, 2010; Silva et al., 2012; Sadorsky, 2011].

Generally, the present study shows that, barring any country level response, changes in RE consumption are transmitted to the sample countries' economies. The claim that macroeconomic activities respond to RE consumption is further confirmed by the VAR Granger causality test in Table 11, which suggests that RE consumption causes economic growth in the sample countries. The table further shows there was a bidirectional Granger causality running from RE consumption to income and from income to RE consumption for all countries. There are positive relationships between RE consumption and economic growth. These findings are consistent with the previous studies' findings for the relationship between RE consumption and income shocks [Apergis, Payne, 2010; 2014; Ohler, Fetters, 2014; Sadorsky, 2009b; Salim, Rafiq, 2012]. In contrast, while Akinlo [Akinlo, 2008] found no Granger causality in either direction between economic growth and energy consumption for Nigeria, some empirical studies such as [Payne, 2011; Menegaki, 2011; Menyah, Wolde-Rufael, 2010] found unidirectional Granger causality between RE consumption and income.

The results further demonstrate that economic welfare enhancement translates to more renewables deployment for the sample countries. The level of these impacts in various countries is also different as these countries respond differently to changes in RE consumption.

Although there is no causality from RE consumption to electricity price, there is causality running from electricity price to RE consumption for Turkey. This study found a unidirectional relationship between RE consumption and electricity prices. Likewise, there is unidirectional causality link between RE consumption and electricity prices for Nigeria. While there is causality for the correlation between 
Figure 2. Impulse Response Functions for the UK
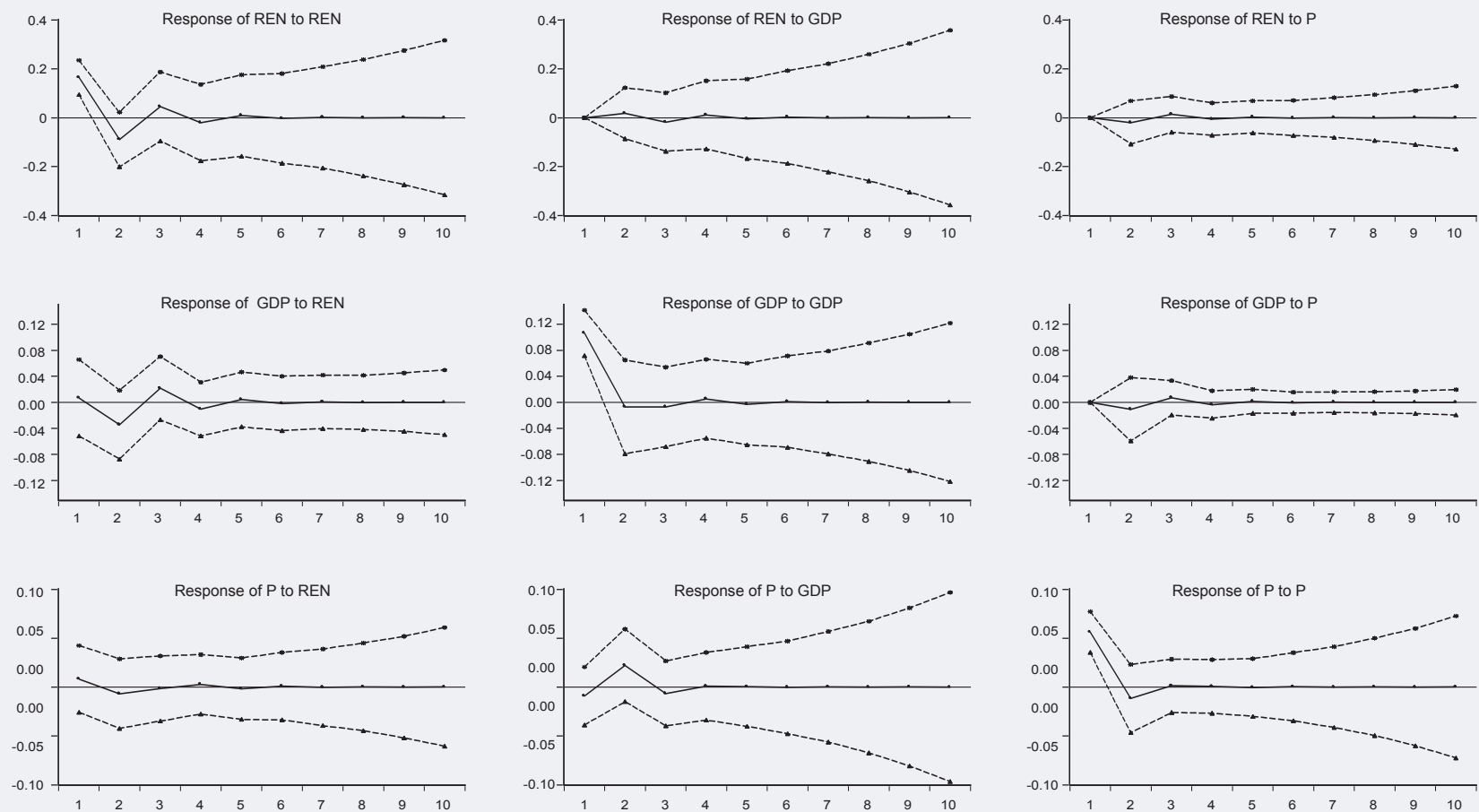

Note: During the period from 3 to 10, the impulse response of RE consumption to a shock in income and price is zero and insignificant, because zero is included in the confidence interval. Diagram 4 represents the impulse response of income to a shock in RE consumption so that in the period from 1 to 3 the response of income to RE shocks is negative and significant, because the confidence interval does not include zero. The impulse response of price to a shock in RE consumption is positive and significant for the period from 1 to 3 and is constant and insignificant.

Source: author's calculations.

\section{Figure 3. Impulse Response Functions for Turkey}
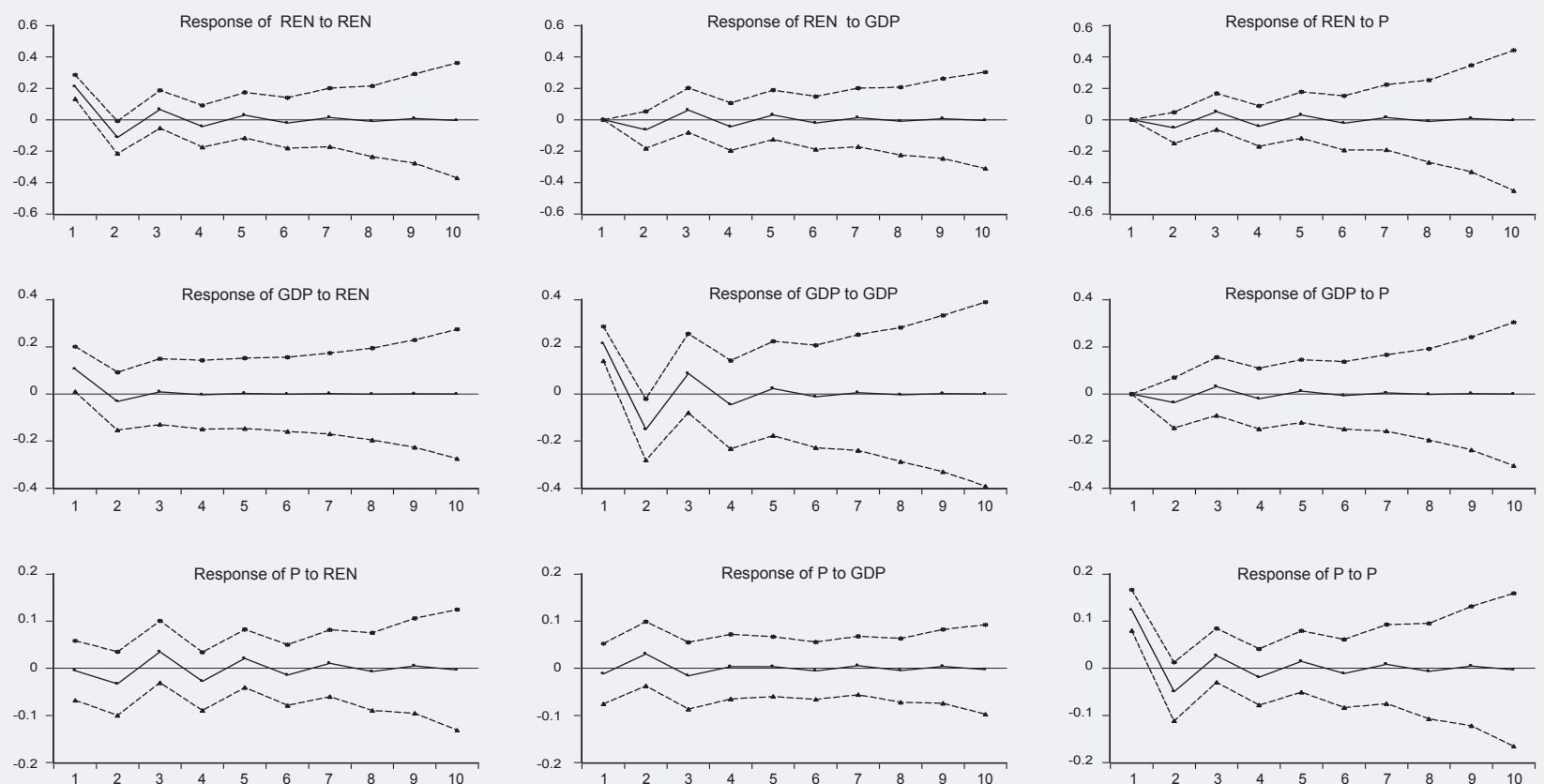

Note: The response of RE consumption to a shock in income and price are positive and statistically significant for 3 years because the confidence interval does not include zero. The response of income to a shock in RE consumption is statistically significant for 1 and 2 years, and then it is zero. The response of price to a shock in RE consumption is positive and statistically significant for 3 to 5 years.

Source: author's calculations. 


\section{Figure 4. Impulse Response Functions for Nigeria}
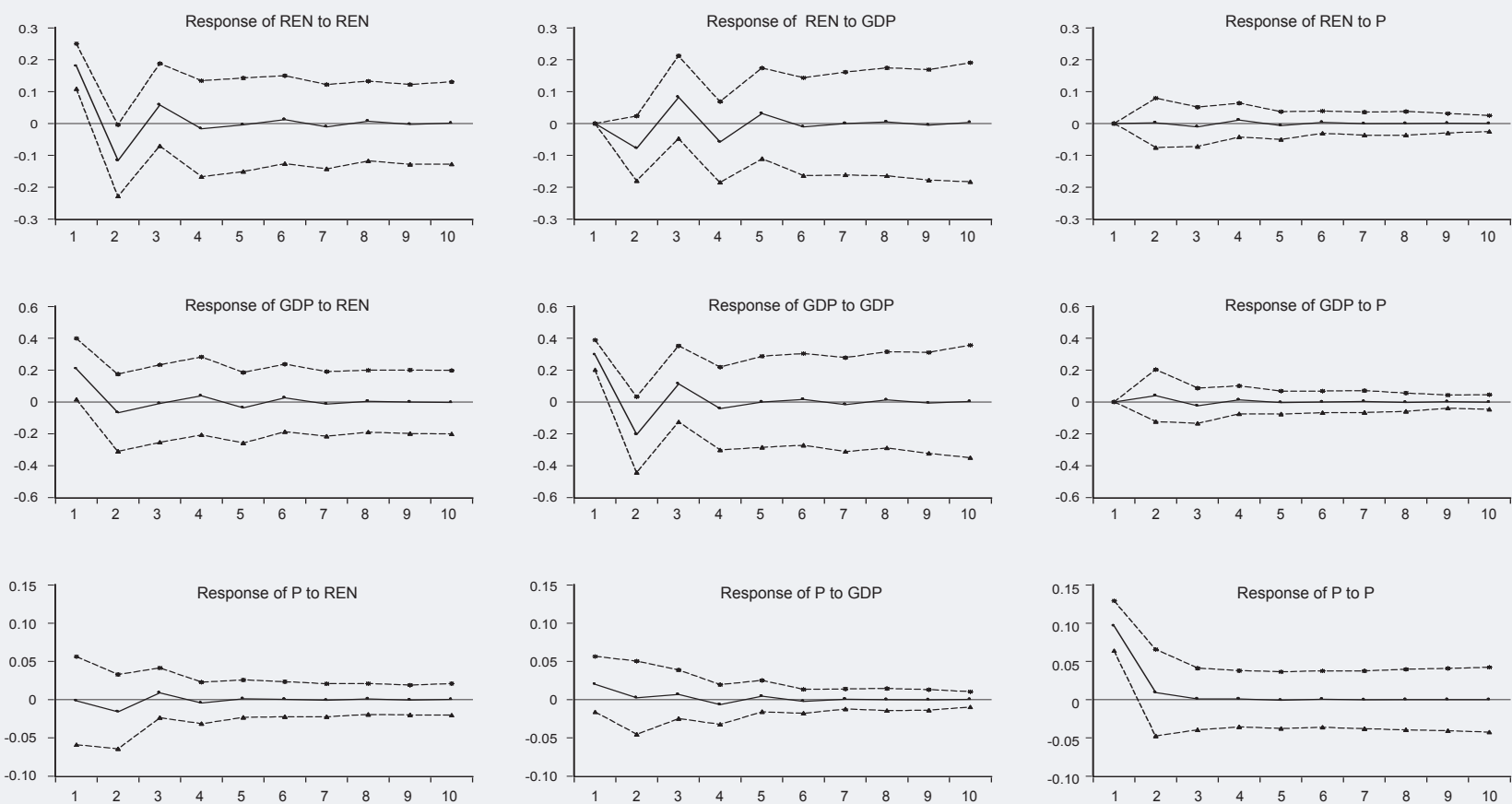

Note: The response of RE consumption to a shock in income is positive for 3 and 4 years and significant at 5\% level, as zero is not included in the confidence interval. The response of RE consumption to a shock in price is zero and statistically insignificant at $5 \%$ level, as the confidence interval contains the value of zero. The response of income to a shock in RE consumption is statistically significant. The response of price to a shock in RE consumption is negative and statistically significant for the period of 3 years, then it is zero.

Source: author's calculations.

\section{Table 10. Variance Decomposition}

\begin{tabular}{|c|c|c|c|c|c|c|}
\hline \multirow{2}{*}{ Step } & \multicolumn{3}{|c|}{ RE consumption response to GDP impulse } & \multicolumn{3}{|c|}{ GDP response to RE consumption impulse } \\
\hline & FEVD & Lower ${ }^{\star}$ & Upper $^{\star}$ & FEVD & Lower $^{*}$ & Upper $^{*}$ \\
\hline 0 & 0 & 0 & 0 & 0 & 0 & 0 \\
\hline 1 & 0 & 0 & 0 & 0.359297 & 0.013927 & 0.704667 \\
\hline 2 & 0.013606 & -0.039131 & 0.066342 & 0.454295 & 0.081983 & 0.826606 \\
\hline 3 & 0.05345 & -0.094369 & 0.20127 & 0.453227 & 0.081536 & 0.824917 \\
\hline 4 & 0.066252 & -0.111242 & 0.243745 & 0.475294 & 0.099743 & 0.850845 \\
\hline 5 & 0.062214 & -0.106638 & 0.231066 & 0.491207 & 0.089595 & 0.892818 \\
\hline 6 & 0.06205 & -0.111837 & 0.235937 & 0.489189 & 0.081451 & 0.896927 \\
\hline 7 & 0.067427 & -0.123816 & 0.258671 & 0.486876 & 0.081447 & 0.892306 \\
\hline 8 & 0.070319 & -0.126972 & 0.267609 & 0.490213 & 0.077361 & 0.903064 \\
\hline 9 & 0.069973 & -0.126466 & 0.266411 & 0.491456 & \begin{tabular}{|l|}
0.073618 \\
\end{tabular} & 0.909293 \\
\hline 10 & 0.070507 & -0.128206 & 0.26922 & 0.491059 & 0.07384 & 0.908278 \\
\hline \multirow{2}{*}{ Step } & \multicolumn{3}{|c|}{ RE consumption response to ptrice impulse } & \multicolumn{3}{|c|}{ Price response to RE consumption impulse } \\
\hline & FEVD & Lower ${ }^{*}$ & \begin{tabular}{|c|} 
Upper \\
\end{tabular} & FEVD & \begin{tabular}{|l|} 
Lower $^{*}$ \\
\end{tabular} & Upper ${ }^{*}$ \\
\hline 0 & 0 & 0 & 0 & \begin{tabular}{|l|l|}
0 \\
\end{tabular} & 0 & 0 \\
\hline 1 & 0 & 0 & 0 & 0.000086 & -0.008263 & 0.008436 \\
\hline 2 & 0.002753 & -0.02596 & 0.031465 & 0.193485 & -0.090817 & 0.477787 \\
\hline 3 & 0.035547 & -0.109357 & 0.180451 & 0.190556 & -0.076611 & 0.457722 \\
\hline 4 & 0.048243 & -0.13047 & 0.226955 & 0.213567 & -0.075414 & 0.502547 \\
\hline 5 & 0.045567 & -0.119104 & 0.210239 & 0.21828 & -0.080995 & 0.517554 \\
\hline 6 & 0.05008 & -0.125819 & 0.225979 & 0.216683 & -0.082071 & 0.515436 \\
\hline 7 & 0.054289 & \begin{tabular}{|l|l|}
-0.13638 \\
\end{tabular} & 0.244959 & 0.216089 & -0.081811 & 0.513988 \\
\hline 8 & 0.054823 & -0.137006 & 0.246652 & 0.217155 & -0.085225 & 0.519534 \\
\hline 9 & 0.054766 & -0.136561 & 0.246093 & 0.218058 & -0.086876 & 0.522992 \\
\hline 10 & 0.056024 & -0.13899 & 0.251038 & 0.218054 & -0.087023 & 0.523131 \\
\hline \multicolumn{7}{|c|}{ Note: ${ }^{*}-95 \%$ lower and upper bounds. } \\
\hline
\end{tabular}


Table 11. Granger Causality Test

\begin{tabular}{|c|c|c|c|}
\hline \multicolumn{4}{|c|}{ Granger Causality Wald tests } \\
\hline Equation & Excluded & Chi2 & Prob $>$ Chi2 \\
\hline \multicolumn{4}{|c|}{$U K$} \\
\hline \multirow{3}{*}{$\begin{array}{l}\text { RE } \\
\text { consumption }\end{array}$} & GDP & 25.396 & 0.000 \\
\hline & Electricity price & 80.805 & 0.000 \\
\hline & All & 112.68 & 0.000 \\
\hline \multirow{3}{*}{ GDP } & RE consumption & 109 & 0.000 \\
\hline & Electricity price & 113.39 & 0.000 \\
\hline & All & 180.89 & 0.000 \\
\hline \multirow{3}{*}{ Electricity price } & RE consumption & 10.759 & 0.029 \\
\hline & \begin{tabular}{|l|} 
GDP \\
\end{tabular} & 15.19 & 0.004 \\
\hline & All & 25.758 & 0.001 \\
\hline \multicolumn{4}{|c|}{ Turkey } \\
\hline \multirow{3}{*}{$\begin{array}{l}\text { RE } \\
\text { consumption }\end{array}$} & GDP & 11.435 & 0.022 \\
\hline & Electricity price & 3.8749 & 0.423 \\
\hline & All & 12.801 & 0.119 \\
\hline \multirow{3}{*}{ GDP } & RE consumption & 19.495 & 0.001 \\
\hline & Electricity price & 17.067 & 0.002 \\
\hline & All & 27.886 & 0.000 \\
\hline \multirow[t]{3}{*}{ Electricity price } & RE consumption & 93.067 & 0.000 \\
\hline & GDP & 34.292 & 0.000 \\
\hline & All & 109.51 & 0.000 \\
\hline \multicolumn{4}{|c|}{ Nigeria } \\
\hline \multirow{3}{*}{$\begin{array}{l}\text { RE } \\
\text { consumption }\end{array}$} & GDP & 47.803 & 0.000 \\
\hline & Electricity price & 14.694 & 0.005 \\
\hline & All & 49.931 & 0.000 \\
\hline \multirow{3}{*}{ GDP } & RE consumption & 24.957 & 0.000 \\
\hline & Electricity price & 20.436 & 0.000 \\
\hline & All & 39.161 & 0.000 \\
\hline \multirow[t]{3}{*}{ Electricity price } & RE consumption & 3.5722 & 0.467 \\
\hline & GDP & 5.0131 & 0.286 \\
\hline & All & 12.546 & 0.128 \\
\hline
\end{tabular}

\section{Table 12. Baseline Forecast of RE Consumption for Three Countries}

\begin{tabular}{|c|r|r|r|}
\hline Years & UK & \multicolumn{1}{c|}{ Turkey } & \multicolumn{1}{c|}{ Nigeria } \\
\hline 2015 & 4.10 & 4.00 & 1.80 \\
\hline 2020 & 4.90 & 4.18 & 1.80 \\
\hline 2025 & 5.82 & 4.32 & 1.79 \\
\hline 2030 & 6.87 & 4.48 & 1.77 \\
\hline Source: author's calculations. \\
\end{tabular}

Figure 5. RE Consumption Forecast for the UK

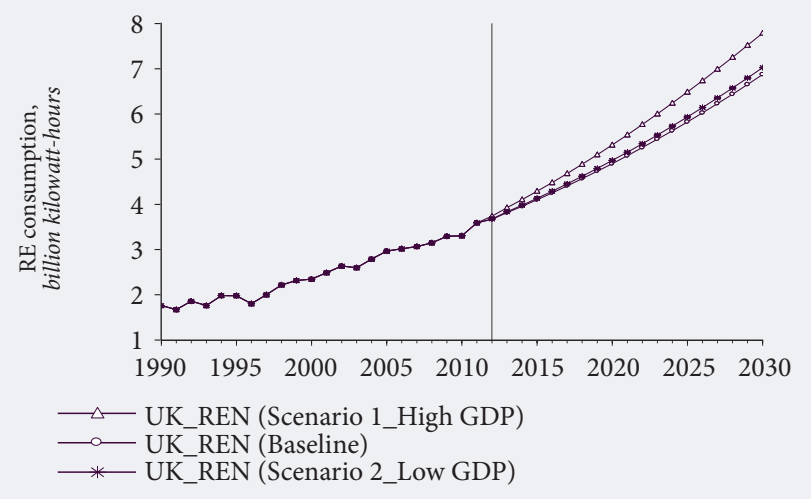

Source: author's calculations.

\section{Figure 6. RE Consumption Forecast for Turkey}

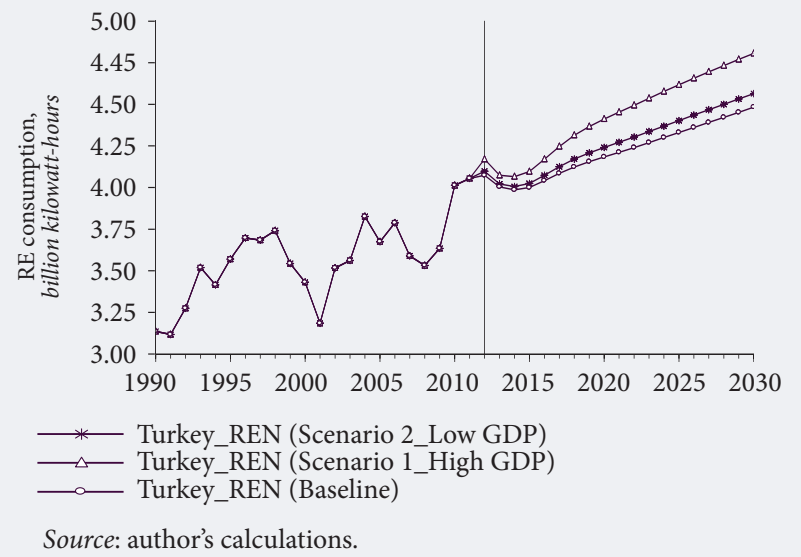

Figure 7. RE Consumption Forecast for Nigeria

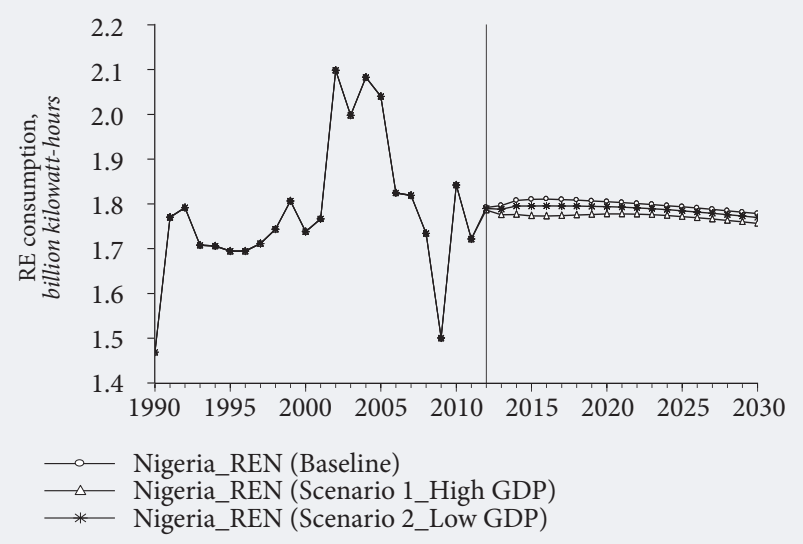

Source: author's calculations.

$\mathrm{RE}$ consumption and electricity prices, there is no causality from electricity price to RE consumption. The result for Nigeria is also consistent with the study of Ebohon [Ebohon, 1996], which showed that price shock does not affect economic activity and energy consumption in Nigeria. For the United Kingdom, there is bidirectional causality in the relationship between RE consumption and electricity prices. Sadorsky (2009a) suggests that in the UK, RE consumption is more responsive to electricity price changes and that a drop in electricity prices encourages RE consumption.

\section{RE Forecasts}

The forecasts for RE energy demand over the period 2013-2030 were based on two VAR model scenarios. Scenario 1 assumes a high level of economic growth, while Scenario 2 assumes a low level of economic 
growth. Growth estimates were based on the World Bank database of annual GDP growth ratio for the countries. These scenarios assume some level of economic growth because many scholars and institutions (such as the IEA, World Bank) anticipate positive growth rates for these countries. This paper used GDP and electricity prices as predictors for the forecast because they play a role in RE consumption.

For RE consumption in the UK, Figure 5 indicates an obvious trend of rising renewable consumption. In 2030, RE consumption is forecast at 6.87 billion kilowatt-hours and for a high and low level of economic growth 7.78 and 7.02 billion kilowatt-hours are forecasted, respectively.

Figure 6 shows the forecasting for RE consumption in Turkey. The forecasting trend graph in Figure 3 shows a steady upward slope for the coming years. In 2030, RE consumption is forecast at 4.48 billion kilowatt-hours while with a high and low level of economic growth 4.81 and 4.56 billion kilowatt-hours are forecasted, respectively. Furthermore, the obvious RE consumption drop in 2001 addressed Turkey's 2000-2001 financial crisis since it may have affected the forecast results.

In Figure 7, the total renewable consumption fluctuated over the period. RE consumption is expected to stabilize in future years. The forecast of RE consumption for Nigeria is basically the historical average. The forecast did not reflect the recent peak in 2003-2005 and the drop in 2009. In 2030, RE consumption is forecast at 1.77 billion kilowatt-hours, while with a high and low level of economic growth 1.75 and 1.76 billion kilowatt-hours are forecasted, respectively.

Based on the vector autoregressive model of the three case study countries, the estimated RE consumption for the years 2015, 2020, 2025, and 2030 are presented in Table 12. The forecast illustrates the apparent growth of consumption of RE in the UK and Turkey, but not in Nigeria.

\section{Conclusions and Policy Implications}

This study investigated the dynamic interaction between RE consumption, income, and electricity prices for the three case study countries employing a standard VAR approach. The study was conducted using the data of the United Kingdom, Turkey, and Nigeria from 1990 to 2012. In this regard, the aim of this paper was to analyze how an increasing share of renewable sources in power generation affects income and price while the forecasts for the case study countries were essential for the completion of this research. The results from IRF indicate that positive shocks to income increase RE consumption. This means that effective economic policies favoring economic growth and development should also lead to increases in RE consumption. The study's results also show that economic growth in the sample countries has a positive relationship with RE consumption.

The policy implications of this study's findings are potentially important for the case study countries because they highlight the importance of increasing RE consumption within the relevant energy portfolios. Thus, it seems that there is a new market emerging in the energy industry with the potential to create major changes in the current traditional energy markets, if not in the short run then certainly in the medium or long run. In this regard, it seems from the review that the gradual growth rates experienced on the RE market in the past are strong indicators about the trends that those markets would also follow in the future with effective policies. One of the more important policy implications of these results is that income variables have a powerful influence upon the development of renewable sources. For instance, government monetary and fiscal policies can increase income and wealth generation by focusing on increasing innovation and productivity. Specifically, case study countries' energy and economic policies should focus on developing or increasing RE investments for future development purposes.

This study has shown that the income effect is positive and it has policy implications economically and politically for the countries. These findings support the advantages of government policies encouraging the use of RE by implementing RE markets and RE portfolio standards to not only improve security and address environmental concerns, but also from a macroeconomic point of view (stable economic growth). Furthermore, RE consumption is determined by the electricity (RE) price in the long run. Given that renewable energy infrastructure is very expensive, countries produce higher priced electricity from RE sources, but most consumers are not prepared to pay such a price.

It is also worth noting the limitations of this study, which include mainly the period 1990 to 2012 . The application of the model with a reduced number of observations, despite its limitations, was in line with previous studies [Silva et al., 2012; Soytas, Sari, 2009]. Furthermore, there are weaknesses in the data on Nigeria as it was very difficult to find robust data for Nigeria. However, the present paper has strong implications for the two other countries with its depth of analysis. The above limitations should be considered in future studies.

\section{References}

Abbott A.J., De Vita G. (2003) Another Piece in the Feldstein - Horioka Puzzle. Scottish Journal of Political Economy, vol. 50, no 1, pp. 68-89.

Akaike H. (1974) A new look at the statistical model identification. IEEE Transactions on Automatic Control, vol. 19, no 6, pp. 716-723. DOI:10.1109/TAC.1974.1100705. 
Akinlo A.E. (2008) Energy consumption and economic growth: Evidence from 11 Sub-Sahara African countries. Energy Economics, vol. 30, no 5, pp. 2391-2400.

Akinlo A.E. (2009) Electricity consumption and economic growth in Nigeria: Evidence from cointegration and cofeature analysis. Journal of Policy Modelling, vol. 31, no 5, pp. 681-693.

Apergis N., Payne J.E. (2010) Renewable energy consumption and economic growth: Evidence from a panel of OECD countries. Energy Policy, vol. 38, pp. 656-660.

Apergis N., Payne J.E. (2014) Renewable energy, output, CO2 emissions, and fossil fuel prices in Central America: Evidence from a nonlinear panel smooth transition vector error correction model. Energy Economics, vol. 42, pp. 226-232.

Aqeel A., Butt M.S. (2001) The relationship between energy consumption and economic growth in Pakistan. AsiaPacific Development Journal, vol. 8, no 2, pp. 101-110.

Aziz M.I.A., Dahalan J. (2015) Oil Price Shocks and Macroeconomic Activities in Asean-5 Countries: A Panel VAR Approach. Eurasian Journal of Business and Economics, vol. 8, no 16, pp. 101-120.

Belke A. Dobnik F., Dreger C. (2011) Energy consumption and economic growth: New insights into the cointegration relationship. Energy Economics, vol. 33, no 5, pp. 782-789.

Bowden N., Payne J.E. (2010) Sectoral analysis of the causal relationship between renewable and non-renewable energy consumption and real output in the US. Energy Sources Part B: Economics, Planning, and Policy, vol. 5, no 4, pp. 400-408.

Bretschenger L. (2010) Energy Prices, Growth, and the Channels in Between: Theory and Evidence (Economics Working Paper Series), Zurich: ETH Zurich.

Brooks C. (2008) Introductory econometrics for finance (2nd ed.), Cambridge: Cambridge University Press.

Bruns S.B., Gross C. (2013) What if energy time series are not independent? Implications for energy-GDP causality analysis. Energy Economics, vol. 40, pp. 753-759.

Chiou-Wei S.Z., Chen C.F., Zhu Z. (2008) Economic growth and energy consumption: Evidence from linear and nonlinear granger causality. Energy Economics, vol. 30, no 6, pp. 3063-3076.

Dickey D.A., Fuller W.A. (1981) Likelihood ratio statistics for autoregressive time series with a unit root. Econometrica, vol. 49, no 4, pp. 1057-1072.

Ebohon O.J. (1996) Energy, economic growth and causality in developing countries. Energy Policy, vol. 24, no 5, pp. 447-453.

Edenhofer O., Hirth L., Knopf B., Pahle M., Schlömer S., Schmid E., Ueckerdt F. (2013) On the economics of renewable energy sources. Energy Economics, vol. 40, no S1, pp. S12-S23.

Enders W. (1995) Applied econometric time series (2nd ed.), London: John Wiley\&Sons Inc.

Ewing B.T., Sari R., Soytas U. (2007) Disaggregate energy consumption and industrial output in the United States. Energy Policy, vol. 35, no 2, pp. 1274-1281.

Giles D. (2011) VAR or VECM When Testing for Granger Causality? Available at: http://davegiles.blogspot.com. tr/2011/10/var-or-vecm-when-testing-for-granger.html, accessed 25.05.2015.

Granger C.W.J. (1980) Testing for causality: A personal viewpoint. Journal of Economic Dynamics and Control, vol. 2, pp. 329-352. DOI:10.1016/0165-1889(80)90069-X.

Gross C. (2012) Explaining the (non-) causality between energy and economic growth in the U.S. - A multivariate sectoral analysis. Energy Economics, vol. 34, no 2, pp. 489-499.

Halicioglu F. (2009) An econometric study of CO-2-emissions, energy consumption, income and foreign trade in Turkey. Energy Policy, vol. 37, no 3, pp. 1156-1164.

Hannan E.J., Quinn B.G. (1979) The Determination of the order of an autoregression. Journal of the Royal Statistical Society, Series B, vol. 41, pp. 190-195.

Hocaoglu F.O., Karanfil F. (2013) A time series-based approach for renewable energy modelling. Renewable and Sustainable Energy Reviews, vol. 28, pp. 204-214.

Huang B.N. Hwang M.J., Yang C.W. (2008) Causal relationship between energy consumption and GDP growth revisited: A dynamic panel data approach. Ecological Economics, vol. 67, no 1, pp. 41-54.

Humphrey W.S., Stanislaw J. (1979) Economic growth and energy consumption in the UK, 1700-1975. Energy Policy, vol. 7, no 1 , pp. 29-42.

Ighodaro C.A. (2010) Co-integration and causality relationship between energy consumption and economic growth: Further empirical evidence for Nigeria. Journal of Business Economics and Management, vol. 11, no 1, pp. 97-111.

Inglesi-Lotz R. (2013) The Impact of Renewable Energy Consumption to Economic Welfare: A Panel Data Application (Department of Economics Working Paper Series 15, March), Pretoria: University of Pretoria.

IRENA (2018a) Renewable energy auctions: Cases from sub-Saharan Africa, Abu Dhabi: International Renewable Energy Agency.

IRENA (2018b) Renewable capacity statistics 2018, Abu Dhabi: International Renewable Energy Agency.

Johnstone N., Haščič I., Popp D. (2010) Renewable energy policies and technological innovation: Evidence based on patent counts. Environmental and Resource Economics, vol. 45, no 1, pp. 133-155.

Kaygusuz K., Yuksek O., Sari A. (2007) Renewable energy sources in the European Union: Markets and capacity. Energy Sources, Part B: Economics, Planning, and Policy, vol. 2, no 1, pp. 19-29.

Kireyev A. (2000) Comparative Macroeconomic Dynamics in the Arab World: A Panel VAR Approach (IMF Working Paper, Middle Eastern Department, WP/00/54), Washington, D.C.: International Monetary Fund.

Lee C.C., Chien M.S. (2010) Dynamic modelling of energy consumption, capital stock, and real income in G7 countries. Energy Economics, vol. 32, no 3, pp. 564-581.

Lee C.C., Chiu Y.B. (2011) Nuclear energy consumption, oil prices, and economic growth: Evidence from highly industrialized countries. Energy Economics, vol. 33, no 2, pp. 236-248.

Marques C.A., Fuinhas J.A. (2011) Do energy efficiency measures promote the use of renewable sources? Environmental Science \& Policy, vol. 15, no 3, pp. 471-481.

Melikoglu M. (2013) Vision 2023: Feasibility analysis of Turkey's renewable energy projection. Renewable Energy, vol. 50 , issue C, pp. 570-575.

Menegaki A.N. (2011) Growth and renewable energy in Europe: A random effect model with evidence for neutrality hypothesis. Energy Economics, vol. 33, no 2, pp. 257-263.

Menyah K., Wolde-Rufael Y. (2010) CO2 emissions, nuclear energy, renewable energy and economic growth in the US. Energy Policy, vol. 38, no 6, pp. 2911-2915.

Mohammadi H., Parvaresh S. (2014) Energy consumption and output: Evidence from a panel of 14 oil-exporting countries. Energy Economics, vol. 41, pp. 41-46.

Narayan P.K., Prasad A. (2008) Electricity consumption-real GDP causality nexus: Evidence from a bootstrapped causality test for 30 OECD countries. Energy Policy, vol. 36, no 2, pp. 910-918. 
Ng S., Perron P. (2001) Lag length selection and the construction of unit root tests with good size and power. Econometrica, vol. 69, no 6, pp. 1519-1554.

Ocal O., Aslan A. (2013) Renewable energy consumption-economic growth nexus in Turkey. Renewable and Sustainable Energy Reviews, vol. 28, pp. 494-499.

Odhiambo N.M. (2010) Energy consumption, prices and economic growth in three SSA countries: A comparative study. Energy Policy, vol. 38, no 5, pp. 2463-2469.

Ohler A., Fetters I. (2014) The causal relationship between renewable electricity generation and GDP growth: A study of energy sources. Energy Economics, vol. 43, issue C, pp. 125-139.

Ozturk I., Acaravci A. (2013) The long run and causal analysis of energy, growth, openness and financial development on carbon emissions in Turkey. Energy Economics, vol. 36, issue C, pp. 262-267.

Pao H.T., Fu H.C. (2013) Renewable energy, non-renewable energy and economic growth in Brazil. Renewable and Sustainable Energy Reviews, vol. 25, pp. 381-392.

Payne J.E., Taylor J.P. (2010) Nuclear energy consumption and economic growth in the US: An empirical note. Energy Sources, Part B: Economics, Planning, and Policy, vol. 5, no 3, pp. 301-307.

Payne J.E. (2011) On biomass energy consumption and real output in the US. Energy Sources, Part B: Economics, Planning, and Policy, vol. 6, no 1, pp. 47-52.

Payne J.E. (2010) Survey of the international evidence on the causal relationship between energy consumption and growth. Journal of Economic Studies, vol. 37, no 1, pp. 53-95.

Perron P. (1988) Trends and random walks in macroeconomic time series: Further evidence from a new approach. Journal of Economic Dynamics and Control, vol. 12, no 2, pp. 297-332.

Phillips P.C., Perron P. (1988) Testing for a unit root in time series regression. Biometrika, vol. 75, no 2, pp. 335-346.

Phillips P.C.B. (1998) Impulse response and forecast error variance asymptotic in nonstationary VARs. Journal of Econometrics, vol. 83, pp. 21-56.

REN21 (2018) Renewables 2018 Global Status Report, Paris: REN21 Secretariat. ISBN 978-3-9818911-3-3.

Sadorsky P. (2009a) Renewable energy consumption, CO2 emissions and oil prices in the G7 countries. Energy Economics, vol. 31, no 3, pp. 456-462.

Sadorsky P. (2009b) Renewable energy consumption and income in emerging economies. Energy Policy, vol. 37, no 10 , pp. 4021-4028.

Sadorsky P. (2011) Modelling renewable energy consumption for a greener global economy. Planet Earth $2011-$ Global Warming Challenges and Opportunities for Policy and Practice (ed. E. Carayannis), Rijeka, Shanghai: InTech, pp. 507-524.

Salim R.A., Rafiq S. (2012) Why do some emerging economies proactively accelerate the adoption of renewable energy? Energy Economics, vol. 34, no 4, pp. 1051-1057.

Schwarz G.E. (1978) Estimating the dimension of a model. Annals of Statistics, vol. 6, no 2, pp. 461-464. DOI:10.1214/ aos/1176344136, MR 0468014.

Silva S., Soares I., Pinho C. (2012) The impact of renewable energy sources on economic growth and CO2 emissions a SVAR approach. European Research Studies, vol. 15 (Special Issue on Energy), pp. 132-144.

Soytas U., Sari R. (2009) Energy consumption, economic growth, and carbon emissions: Challenges faced by an EU candidate member. Ecological Economics, vol. 68, no 6, pp. 1667-1675.

Taylor J.W. (2010) Triple seasonal methods for short-term electricity demand forecasting. European Journal of Operational Research, vol. 204, pp. 139-152.

Tiwari A.K. (2011) A structural VAR analysis of renewable energy consumption, real GDP and CO2 emissions: Evidence from India. Economics Bulletin, vol. 31, no 2, pp. 1793-1806.

Tugcu C.T., Ozturk I., Aslan A. (2012) Renewable and non-renewable energy consumption and economic growth relationship revisited: Evidence from G7 countries. Energy Economics, vol. 34, no 6, pp. 1942-1950.

Vaona A. (2012) Granger non-causality tests between (non) renewable energy consumption and output in Italy since 1861: The (ir) relevance of structural breaks. Energy Policy, vol. 45, pp. 226-236.

Ward D.J., Inderwildi O.R. (2013) Global and local impacts of UK renewable energy policy. Energy Environment Science, vol. 6, pp. 18-24.

World Bank (2013) World Development Indicators 2013. Available at: http://data.worldbank.org/, accessed 10.10.2014.

Yildirim E., Sarac S., Aslan A. (2012) Energy consumption and economic growth in the USA: Evidence from renewable energy. Renewable and Sustainable Energy Reviews, vol. 16, no 9, pp. 6770-6774.

Yusuf S.A. (2014) Impact of energy consumption and environmental degradation on economic growth in Nigeria (MPRA Paper 55529), Munchen: University of Munchen. 